\title{
Urinary tract infections in pregnancy in a rural population of Bangladesh: population- based prevalence, risk factors, etiology, and antibiotic resistance
}

Anne CC Lee ${ }^{1 *}$ (D) Luke C. Mullany ${ }^{2}$, Alain K. Koffi ${ }^{2}$, Iftekhar Rafiqullah ${ }^{3}$, Rasheda Khanam², Lian V. Folger ${ }^{1}$, Mahmoodur Rahman ${ }^{4}$, Dipak K. Mitra ${ }^{5}$, Alain Labrique ${ }^{2}$, Parul Christian²,6, Jamal Uddin ${ }^{7}$, Parvez Ahmed ${ }^{8}$, Salahuddin Ahmed ${ }^{9}$, Arif Mahmud ${ }^{10}$, Sushil K. DasGupta ${ }^{4}$, Nazma Begum², Mohammad A. Quaiyum ${ }^{4}$ Samir K. Saha ${ }^{11}$ and Abdullah H. Baqui ${ }^{2}$

\begin{abstract}
Background: Urinary tract infection (UTI) in pregnancy, including asymptomatic bacteriuria, is associated with maternal morbidity and adverse pregnancy outcomes, including preterm birth and low birthweight. In low-middle income countries (LMICS), the capacity for screening and treatment of UTIs is limited. The objective of this study was to describe the population-based prevalence, risk factors, etiology and antimicrobial resistance patterns of UTIs in pregnancy in Bangladesh.

Methods: In a community-based cohort in Sylhet district, Bangladesh, urine specimens were collected at the household level in 4242 pregnant women (<20 weeks gestation) for culture and antibiotic susceptibility testing. Basic descriptive analysis was performed, as well as logistic regression to calculate adjusted odds ratios (aOR) for UTI risk factors.
\end{abstract}

Results: The prevalence of UTI was 8.9\% (4.4\% symptomatic UTI, 4.5\% asymptomatic bacteriuria). Risk factors for UTI in this population included maternal undernutrition (mid-upper arm circumference $<23 \mathrm{~cm}$ : aOR=1.29, 95\% Cl: 1.03-1.61), primiparity ( $\mathrm{aOR}=1.45,95 \% \mathrm{Cl}: 1.15-1.84$ ), and low paternal education (no education: $\mathrm{aOR}=1.56,95 \% \mathrm{Cl}$ : 1.09-2.22). The predominant uro-pathogens were E. coli (38\% of isolates), Klebsiella (12\%), and staphyloccocal species (23\%). Group B streptococcus accounted for 5.3\% of uro-pathogens. Rates of antibiotic resistance were high, with only two-thirds of $E$. coli susceptible to $3^{\text {rd }}$ generation cephalosporins.

Conclusions: In Sylhet, Bangladesh, one in 11 women had a UTI in pregnancy, and approximately half of cases were asymptomatic. There is a need for low-cost and accurate methods for UTI screening in pregnancy and efforts to address increasing rates of antibiotic resistance in LMIC.

Keywords: Urinary tract infection, Asymptomatic bacteriuria, Bangladesh, Pregnancy, Maternal morbidity, Risk factors, Antimicrobial resistance

\footnotetext{
* Correspondence: alee6@bwh.harvard.edu

'Department of Pediatric Newborn Medicine, Brigham and Women's

Hospital, 75 Francis Street, Boston, MA 02115, USA

Full list of author information is available at the end of the article
}

(c) The Author(s). 2019 Open Access This article is distributed under the terms of the Creative Commons Attribution 4.0 International License (http://creativecommons.org/licenses/by/4.0/), which permits unrestricted use, distribution, and reproduction in any medium, provided you give appropriate credit to the original author(s) and the source, provide a link to the Creative Commons license, and indicate if changes were made. The Creative Commons Public Domain Dedication waiver (http://creativecommons.org/publicdomain/zero/1.0/) applies to the data made available in this article, unless otherwise stated. 


\section{Background}

Urinary tract infections (UTI) in pregnancy are a large and under-emphasized risk factor for pregnancy morbidity and adverse birth outcomes in low- and middle-income country (LMIC) settings [1]. UTI may present in pregnancy with symptoms of acute cystitis or pyelonephritis, or may be more insidious in women with asymptomatic bacteriuria (ASB). Screening and treatment of ASB by urine culture is recommended for all women at least once in early pregnancy in high-income countries, by the Infectious Diseases Society of America [2], Canadian Task Force on Preventive Care [3], and National Institute of Health and Clinical Excellence of the United Kingdom (UK) [4]. In low-income countries, screening and treatment of UTI or ASB is challenging due to the costs and logistics of performing urine culture. Recently, the World Health Organization (WHO) made context-specific antenatal care recommendations for screening and treatment of ASB in LMIC [5], recommending urine culture in settings with capacity, or mid-stream urine Gram stain, and treatment of ASB.

There is a paucity of population-based data on the prevalence and etiology of UTI in pregnancy in lowmiddle income countries. In a recent review, the global prevalence of UTI and/or ASB in pregnancy ranged from 3 to $35 \%$ across 5 continents in countries with preterm birth rates $>10 \%$ [1]. Women carry higher risk of UTI than men, and pregnancy places women at increased risk of ascending infection due to the weight of the fetus and dilation of the ureters and renal pelvis [6, 7]. Before urine culture was standard of care in the US (1960's), pyelonephritis developed in 40\% of pregnant women with untreated bacteriuria [8]. Maternal urinary tract infections may trigger an inflammatory response, including the release of chemokines and cytokines that may result in decidual activation, prostaglandin release, and cervical ripening, thereby increasing the risk of preterm birth [9]. In historical studies, approximately 30$50 \%$ of women with pyelonephritis delivered preterm [10-12]. ASB is significantly associated with preterm delivery (RR 2.00, 95\% CI 1.43-2.77) [13], and low birthweight (RR 1.54, 95\% CI 1.35-1.75); however, evidence for the impact of ASB screening and treatment on preterm birth risk has been graded as weak [14]. In addition, maternal UTI has been associated with increased risk of stillbirth [15] and early onset neonatal sepsis [16].

We recently screened pregnant women for UTI as part of a cluster-randomized controlled trial (clinicaltrials.gov identifier: NCT01572532) designed to evaluate the impact of a community-based antenatal screening and treatment program for genito-urinary tract infections in early pregnancy on population-level rates of preterm birth in rural Sylhet district, Bangladesh $[17,18]$. In this manuscript, we describe the population-based prevalence, risk factors, etiology, and antimicrobial resistance patterns of UTIs in this cohort.

\section{Methods \\ Study population and study design}

The data reported in this manuscript were part of a population-based cluster randomized controlled trial (cRCT) to determine the impact of an antenatal screening program for abnormal vaginal flora and UTI on the incidence of preterm live birth (clinicaltrials.gov identifier: NCT01572532) [14, 15]. The study protocol was approved by the institutional review boards of Johns Hopkins Bloomberg School of Public Health Institutional Review Board (Baltimore, Maryland), International Centre for Diarrhoeal Disease Research, Bangladesh Ethical Review Committee (iccdr,b) (Dhaka, Bangladesh), and Partners Human Research Committee (Boston, MA). The Maternal Infection Screening and Treatment (MIST) study [17] was conducted between January 2, 2012 and July 28, 2015 in two rural sub-districts of Sylhet district, Bangladesh: Zakiganj and Khanaighat, which are part of the Projahnmo research site. The study site is in a rural, agrarian area, with poor access to health care and high need, having one of the highest neonatal mortality rates in Bangladesh. Health services in Bangladesh are provided by the government's Ministry of Health and Family Welfare, NGOs, and private providers. According to the 2014 Bangladesh Demographic and Health Survey, $79 \%$ of pregnant women had at least one ANC visit and 31\% received at least four ANC visits [19]. Screening for urinary tract infection in pregnancy by urine culture is not standard of care in Bangladesh.

A cluster was defined as the area served by a community health worker (CHW), comprising several contiguous villages (population 4000 people, approximately 120 annual pregnancies, per cluster). In MIST, there were 24 clusters, for which community health workers conducted home visits to provide basic antenatal and post-partum care and education. In the cRCT, 12 clusters were randomized to receive the intervention, which included home-based screening and treatment of UTI and abnormal vaginal flora (AVF). In this manuscript, we report the results of the UTI screening. Results of the AVF intervention are reported elsewhere [20].

\section{Pregnancy surveillance}

All married women of reproductive age in the study areas were under routine monthly community-based pregnancy surveillance through the duration of the study. Pregnant women who had no or uncertain recall of their last menstrual period (LMP), LMP > 19 weeks, self-reported history of irregular bleeding due to injectable 
depoprovera, or self-reported history of severe chronic disease were excluded. Participants were enrolled after providing verbal informed consent. Verbal consent was obtained because the majority of the prospective study population was illiterate at the initiation of the study. Documentation of verbal informed consent was formally approved by all institutional review boards.

\section{Urinary tract infection screening}

For pregnant women in intervention clusters, during a home visit at $<19$ weeks gestation, a clean catch midstream urine specimen was collected for culture. The CHW instructed the mother to spread the labia widely before collecting $20-30 \mathrm{~mL}$ of the midstream urine into a sterile wide-mouthed container. The urine specimen was immediately placed in a cooler refrigerated with icepacks $\left(\sim 2\right.$ to $\left.8^{\circ} \mathrm{C}\right)$ and transported to the Sylhet field laboratory, maintaining the cold chain. A random selection of $10 \%$ of the control arm women also had urine screened by culture.

\section{Laboratory testing}

Urine specimens were inoculated on standard MacConkey and Blood agar plates within $6 \mathrm{~h}$ of collection and incubated at $37^{\circ} \mathrm{C}$ for $48 \mathrm{~h}$. Bacterial growth was quantified twice ( 24 and $48 \mathrm{~h}$ ). Bacterial isolates were speciated using standard microbial techniques. Antibiotic susceptibility testing was performed on Mueller-Hinton agar plates following standard laboratory protocols. The disk diffusion method was used; zones of growth inhibition were measured in $\mathrm{mm}$ [21]. The antimicrobial discs used were: cefixime, nitrofurantoin, ampicillin, azithromycin, cotrimoxazole, gentamycin, nalidixic acid, ceftriaxone, and cephalexin.

\section{Definitions}

We defined categories of urinary tract infection shown in Table 1. The list of organisms that we considered as UTI pathogens versus contaminants is shown in Additional file 1: Table S1.

\section{UTI treatment}

The MIST treatment algorithm for positive urine cultures is shown in Additional file 1: Figure S1. UTI was treated in pregnant women with high burden growth (> $10^{5} \mathrm{CFU} / \mathrm{mL}$ of a uro-pathogen), as well as among women with intermediate growth who had UTI symptoms, as per ACOG recommendations [22]. From January to October 2012, the first line antibiotic treatment was cefixime $400 \mathrm{mg}$ po once daily for 3 days. After observing that only two-thirds of $E$. coli were susceptible to cefixime, the first-line treatment was then changed to nitrofurantoin (Macrobid) $100 \mathrm{mg}$ po bid for 7 days. All symptomatic women were also referred to the subdistrict hospital for further evaluation and management.

A test of cure was obtained 1 week after antibiotic completion for all pregnant women with positive cultures. If the second urine culture remained positive, the supervising field physician prescribed an antibiotic based on the antimicrobial sensitivity pattern. Persistent UTI after twice-repeated treatment was referred to Sylhet Osmani Medical College Hospital for further evaluation and management.

\section{Data analysis}

Simple descriptive statistics were used to describe the distribution of uro-pathogens and antibiotic sensitivity patterns.

For the risk factor analysis, the primary outcome was UTI requiring antibiotic treatment, as defined in Table 1. We included a number of socio-demographic characteristics, nutrition, behavior, and reproductive history variables as potential risk factors. Socio-demographic characteristics included household wealth, household size, religion, woman's age at enrollment, parity, and educational attainment of both the woman and her husband. All variables were categorized. A wealth index indicative of relative economic status of the household within the study population was constructed using household facilities and assets weighted with principal component analysis [23]; the households were categorized into quintiles. Comparisons

Table 1 Clinical Categories of Urinary Tract Infection, Based on Culture Growth and Symptoms

\begin{tabular}{ll}
\hline UTI Terminology & Definition \\
\hline High-burden growth & bacteriuria of $>10^{5}$ colony forming units (CFU) per $1 \mathrm{~mL}$ of urine of a single uropathogen [22] \\
Intermediate growth & bacteriuria with $>10^{3}-10^{5} \mathrm{CFU} / \mathrm{mL}$ of a single uropathogen \\
Contamination & bacterial growth of $>1$ micro-organism OR growth of a non-urinary tract pathogen (Additional file 1: Table S1) \\
UTI symptoms & dysuria, urinary frequency, hematuria, abdominal pain, fever, OR flank pain \\
Symptomatic intermediate growth & women with intermediate burden growth and UTI symptoms (as above) \\
Asymptomatic Bacteriuria & women with high burden bacterial growth without UTI symptoms \\
Cystitis & women with positive urine culture (high burden or intermediate growth) and symptoms of dysuria, \\
& urinary frequency, hematuria, urinary urgency or suprapubic tenderness, without upper urinary tract \\
Pyelonephritis & womptoms (fever, chills, flank or back pain) [22] \\
\hline
\end{tabular}


of proportions between groups were analyzed by chisquared statistic.

Risk factors with $p<0.05$ in bivariate analysis were included in multivariate analysis. Logistic regression was performed to calculate adjusted odds ratios (aORs) and 95\% confidence intervals using STATA version 14.0 (StataCorp LP, College Station, TX).

\section{Results}

Figure 1 shows a flow chart of patient enrollment and specimens collected as part of the study intervention. The overall rate of urine culture contamination was
4.9\% (208/4242). These specimens were excluded from the results reported in Table 2, which report on the first adequate, non-contaminated urine specimens $(n=4034)$.

\section{Prevalence of UTI}

In the initial screening of urine samples from the general pregnancy population ( $\mathrm{n}=4034), 230(5.7 \%)$ women had high burden (>100,000 CFU/mL) bacteriuria, among which 47 (20.4\%) reported clinical signs of UTI, and 183 (79.6\%) had no symptoms (Table 2). An additional 599 (14.9\%) women in the initial screening had intermediate level (>1000-<100,000 CFU/mL) bacteriuria, with 130

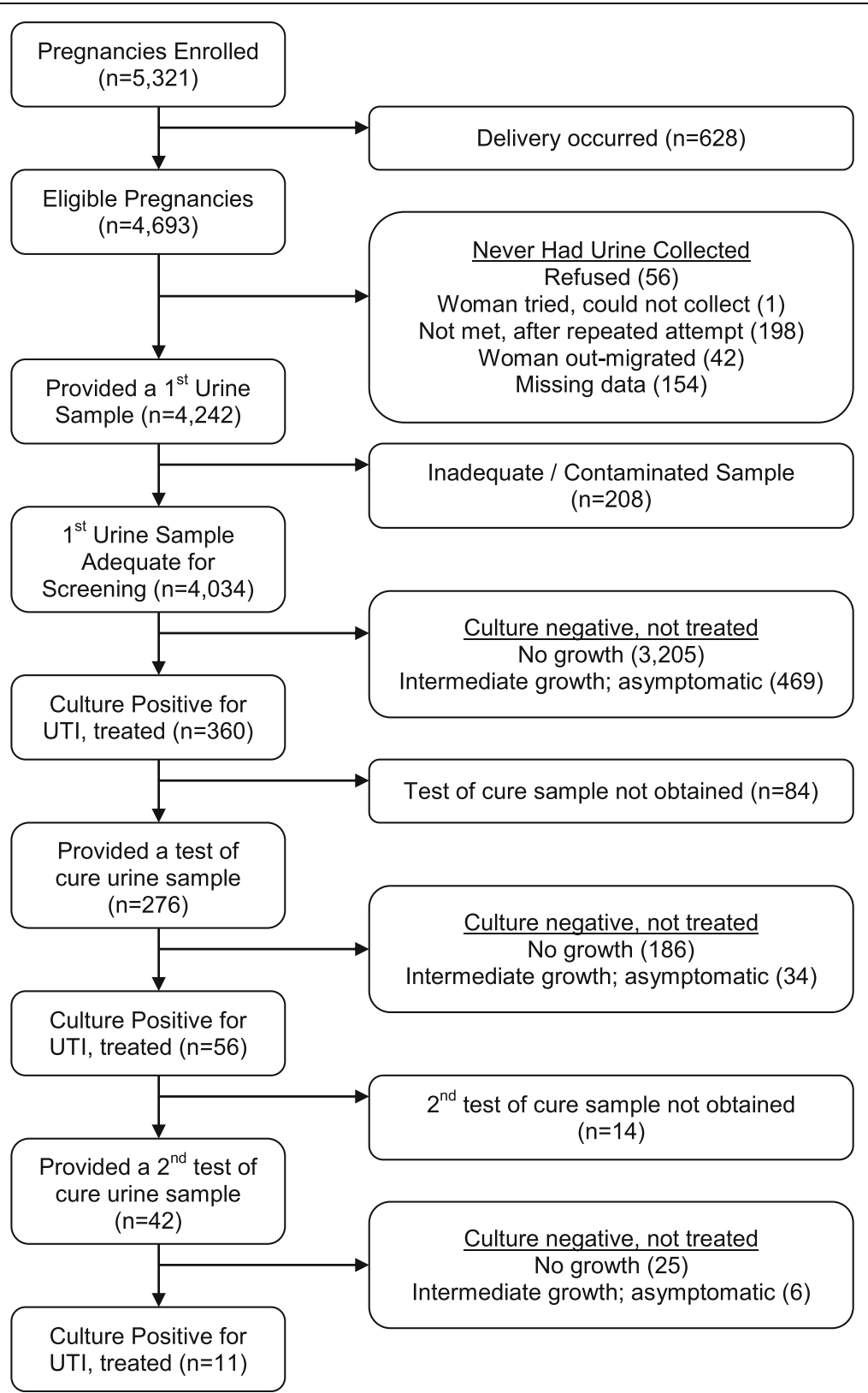

Fig. 1 CONSORT Flow Diagram for MIST Study UTI Samples 
Table 2 Prevalence of UTI

\begin{tabular}{|c|c|c|c|}
\hline & Number & Percent & $95 \% \mathrm{Cl}(\%)$ \\
\hline First adequate screening specimen ${ }^{a}$ & 4034 & & \\
\hline$>100,000$ CFU/mL, symptomatic & 47 & 1.2 & $0.9-1.5$ \\
\hline$>100,000$ CFU/mL, asymptomatic & 183 & 4.5 & $3.9-5.2$ \\
\hline $1000-<100,000 \mathrm{CFU} / \mathrm{mL}$, symptomatic & 130 & 3.2 & $2.7-3.8$ \\
\hline $1000-<100,000$ CFU/mL, asymptomatic & 469 & 11.6 & $10.7-12.6$ \\
\hline No Growth (Normal) & 3205 & 79.5 & $78.2-80.7$ \\
\hline First Test of cure specimen & 276 & & \\
\hline$>100,000$ CFU/mL, symptomatic & 5 & 1.8 & $0.8-4.3$ \\
\hline$>100,000$ CFU/mL, asymptomatic & 36 & 13.0 & $9.6-17.7$ \\
\hline $1000-<100,000 \mathrm{CFU} / \mathrm{mL}$, symptomatic & 15 & 5.4 & $3.3-8.9$ \\
\hline $1000-<100,000 \mathrm{CFU} / \mathrm{mL}$, asymptomatic & 34 & 12.3 & $9.0-16.9$ \\
\hline No Growth (Normal) & 186 & 67.4 & $62.1-73.2$ \\
\hline Second Test of cure specimen & 42 & & \\
\hline$>100,000$ CFU/mL, symptomatic & 2 & 4.8 & $1.2-18.4$ \\
\hline$>100,000$ CFU/mL, asymptomatic & 8 & 19.0 & $10.2-35.5$ \\
\hline 1000- < 100,000 CFU/mL, symptomatic & 1 & 2.4 & $0.3-16.5$ \\
\hline $1000-<100,000 \mathrm{CFU} / \mathrm{mL}$, asymptomatic & 6 & 14.3 & $6.8-30.0$ \\
\hline No Growth (Normal) & 25 & 59.5 & $46.4-76.4$ \\
\hline
\end{tabular}

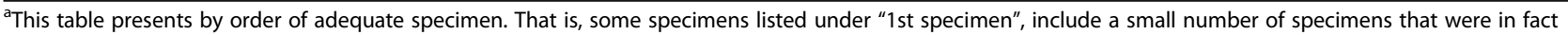
second specimen collected (but represented first testable/non-contaminated specimen)

(21.7\%) of those women reporting UTI symptoms, which were treated with antibiotics. Overall, $360(8.9 \%)$ of women required treatment for UTI, of whom $308(86 \%)$ were started on antibiotics and $284(92 \%)$ completed the full course.

Among women with positive screening urine cultures, we successfully obtained a test of cure specimen in 276/ 360 women. Among these mothers, 56/276 (20.3\%) had a persistent UTI on the second urine culture that required a second course of antibiotics, that was selected based on antimicrobial resistance patterns. Among these women, we obtained a final test of cure specimen from 42 women with persistent UTI. The prevalence of persistent UTI among those women was $26.2 \%$ on the final screening.

\section{Risk factors for UTI}

Table 3 shows the analysis of risk factors for UTI in this population. In bivariate analysis, low household wealth, primiparity, and maternal undernutrition as measured by MUAC were associated with increased risk of UTI. Higher education of the women and their husbands were protective for UTI. In multivariate analysis (Table 4), low MUAC, low paternal education, and primiparity remained statistically significant risk factors for UTI.

\section{Etiology of UTI}

Figure 2 shows the bacterial etiology of UTI pathogens among pregnant mothers who were treated (high burden and intermediate growth in symptomatic mothers; $n=$ 360 ) in the initial screening of the general pregnancy population in Sylhet, Bangladesh. The predominant micro-organisms were E. coli $(n=135 ; 38 \%$ of isolates) and Staphylococcus species (non-aureus) ( $n=82 ; 23 \%$ ), followed by Klebsiella species $(n=44,12 \%)$. Staphylococcus aureus was common, isolated in 42 (12\%) women with UTI. The prevalence of Group B Streptococcus (GBS) bacteriuria was generally lower, with 19 isolates $(n=19 ; 5.3 \%)$.

Among the intermediate growth in mothers who were asymptomatic, there was a predominance of skin contaminants, including staph and strep species, and these are shown in the Additional file 1: Figure S2.

\section{Antimicrobial susceptibility patterns}

Table 5 shows the antimicrobial susceptibility patterns of uro-pathogens in the MIST study. E. coli isolates had low rates of susceptibility to ampicillin (34\% of isolates) and azithromycin (28\%); susceptibility to cefixime, cotrimoxazole, and cephalexin were in the moderate range $(69,63$, and $62 \%$ respectively). The majority of species were highly susceptible to nitrofurantoin, with the exception of Klebsiella species, where $74 \%$ of strains were susceptible. Rates of susceptibility to azithromycin were low among the gramnegative species. 
Table 3 Distribution of potential risk factors by UTI status, bivariate analysis

\begin{tabular}{|c|c|c|c|c|}
\hline & Total & No UTI $(N=3674)$ & UTI $(N=360)$ & $x^{2}$ (p-value) \\
\hline \multicolumn{5}{|l|}{ Socio-demographic characteristic } \\
\hline \multicolumn{5}{|l|}{ Household wealth quintiles (missing: 1) } \\
\hline Lowest tertile & 1361 & 1217 (89.4\%) & $144(10.6 \%)$ & \multirow[t]{3}{*}{$7.867(0.0196)$} \\
\hline Middle tertile & 1335 & $1220(91.4 \%)$ & $115(8.6 \%)$ & \\
\hline Highest tertile & 1338 & 1237 (92.5\%) & $101(7.6 \%)$ & \\
\hline \multicolumn{5}{|l|}{ Hand washing station (missing; 0) } \\
\hline No & 3924 & 3575 (91.1\%) & 349 (8.9\%) & \multirow[t]{2}{*}{$0.161(0.688)$} \\
\hline Yes & 110 & 99 (90.0\%) & $11(10.0 \%)$ & \\
\hline \multicolumn{5}{|l|}{ Household size (missing: 1) } \\
\hline 1-3 household members & 649 & $584(90.0 \%)$ & $65(10.0 \%)$ & \multirow[t]{3}{*}{$2.529(0.283)$} \\
\hline 4-6 household members & 1730 & 1589 (91.9\%) & $141(8.1 \%)$ & \\
\hline $7+$ household members & 1654 & $1500(90.7 \%)$ & $154(9.3 \%)$ & \\
\hline \multicolumn{5}{|l|}{ Low MUAC at enrollment (missing: 8) } \\
\hline No & 2419 & $2228(92.1 \%)$ & $191(7.9 \%)$ & \multirow[t]{2}{*}{$7.782(0.005)$} \\
\hline Yes & 1607 & 1439 (89.6\%) & $168(10.4 \%)$ & \\
\hline \multicolumn{5}{|l|}{ Religion (missing: 1) } \\
\hline Islam & 3871 & $3527(91.1 \%)$ & $344(8.9 \%)$ & \multirow[t]{2}{*}{$0.187(0.665)$} \\
\hline Other & 162 & $146(90.1 \%)$ & $16(9.9 \%)$ & \\
\hline \multicolumn{5}{|l|}{ Mother's age at enrollment (missing: 0) } \\
\hline$<20$ & 381 & $341(89.5 \%)$ & $40(10.5 \%)$ & \multirow[t]{3}{*}{$2.044(0.360)$} \\
\hline $20-29$ & 2567 & 2349 (91.5\%) & $218(8.5 \%)$ & \\
\hline 30 or more & 1086 & $98490.6 \%)$ & $102(9.4 \%)$ & \\
\hline \multicolumn{5}{|l|}{ Mother's education (missing: 0) } \\
\hline No Education (0 years) & 786 & $695(88.4 \%)$ & $91(11.6 \%)$ & \multirow[t]{3}{*}{$10.280(0.0059)$} \\
\hline Primary Education ( $1-5$ years) & 1522 & 1385 (91.0\%) & $137(9.0 \%)$ & \\
\hline Secondary or higher Education (6+) & 1726 & 1594 (92.4\%) & $132(7.6 \%)$ & \\
\hline \multicolumn{5}{|l|}{ Husband's education (missing: 0 ) } \\
\hline No Education (0 years) & 1360 & $1213(89.2 \%)$ & $147(10.8 \%)$ & \multirow[t]{3}{*}{$15.665(0.0004)$} \\
\hline Primary Education ( $1-5$ years) & 1572 & $1428(90.8 \%)$ & $144(9.2 \%)$ & \\
\hline Secondary or higher Education (6+ years) & 1102 & $1033(93.7 \%)$ & $69(6.3 \%)$ & \\
\hline \multicolumn{5}{|l|}{ Reproductive and sexual history } \\
\hline \multicolumn{5}{|l|}{ Primiparous at enrollment (missing: 1 ) } \\
\hline No & 2710 & $2486(91.7 \%)$ & $224(8.3 \%)$ & \multirow[t]{2}{*}{$4.436(0.035)$} \\
\hline Yes & 1323 & 1187 (89.7\%) & $136(10.3 \%)$ & \\
\hline \multicolumn{5}{|l|}{ Hormonal contraceptive history (missing: 0) } \\
\hline No & 3964 & 3611 (91.1\%) & $353(8.9 \%)$ & \multirow[t]{2}{*}{$0.101(0.7501)$} \\
\hline Yes & 70 & $63(90.0 \%)$ & $7(10.0 \%)$ & \\
\hline
\end{tabular}

\section{Discussion}

In a cohort of pregnant women in rural Sylhet, Bangladesh, the prevalence of UTI in early pregnancy was $8.9 \%(4.4 \%$ symptomatic UTI, $4.5 \%$ asymptomatic bacteriuria). A majority of women with bacteriuria in pregnancy were asymptomatic. Risk factors for UTI in this population included maternal undernutrition, primiparity, and low paternal education. The common uro-pathogens were similar to those reported in other geographies, with a predominance of gram negatives, including E. coli and Klebsiella, as well as staphyloccocal species. Group B streptococcus accounted for only $5.3 \%$ of uro-pathogens. Rates of antibiotic resistance were high, with greater than $30 \%$ of $E$. coli resistant to 3rd generation cephalosporins. 
Table 4 UTI Risk Factors, Multivariate Analysis

\begin{tabular}{|c|c|c|}
\hline & Odds Ratio & 95\% Confidence Interval \\
\hline \multicolumn{3}{|l|}{ Household wealth tertiles } \\
\hline Lowest tertile & 1.05 & $0.75-1.48$ \\
\hline Middle tertile & 0.96 & $0.71-1.30$ \\
\hline Highest tertile & 1.00 & - \\
\hline \multicolumn{3}{|l|}{ Low MUAC $(<23 \mathrm{~cm})$ at enrollment } \\
\hline No & 1.00 & - \\
\hline Yes & 1.29 & $1.03-1.61$ \\
\hline \multicolumn{3}{|l|}{ Mother's education } \\
\hline No Education (0 years) & 1.36 & $0.94-1.96$ \\
\hline Primary Education ( $1-5$ years) & 1.11 & $0.85-1.47$ \\
\hline Secondary or higher Education (6+) & 1.00 & - \\
\hline \multicolumn{3}{|l|}{ Husband's education } \\
\hline No Education (0 years) & 1.56 & $1.09-2.22$ \\
\hline Primary Education ( $1-5$ years) & 1.42 & $1.04-1.94$ \\
\hline Secondary or higher Education (6+ years) & 1.00 & - \\
\hline \multicolumn{3}{|l|}{ Primiparous at enrollment } \\
\hline No & 1.00 & - \\
\hline Yes & 1.45 & $1.15-1.84$ \\
\hline
\end{tabular}

The prevalence of UTI/ASB in our study population was comparable to other studies in South Asia. In our study, we sampled all pregnant women identified from households in the study catchment area. This differs from the majority of studies, which recruited pregnant women presenting at ANC clinics or tertiary care facilities. One Bangladeshi study recruiting from ANC clinics reported a $5 \%$ bacteriuria rate, with $1 \%$ of women presenting with UTI symptoms [24]. Reports from urban and rural Rajshahi district, Bangladesh reported that 4$12 \%$ of women presenting to antenatal care had asymptomatic bacteriuria $[25,26]$. In a study of mothers at an ANC clinic in rural Nagpur, India the culture-positive UTI (symptomatic and asymptomatic) prevalence was

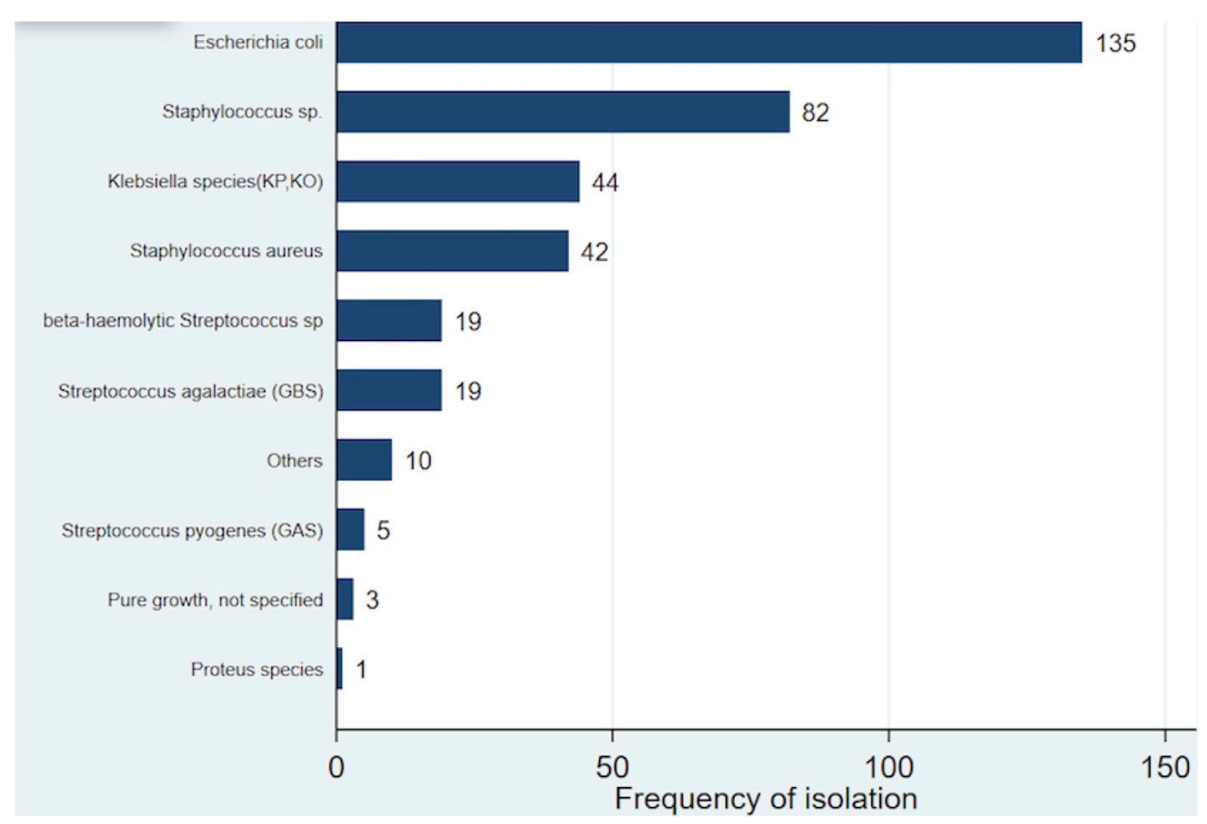

Fig. 2 UTI Pathogens in First Adequate Urine Screening 
Table 5 Antibiotic Susceptibility Patterns of Uropathogens in the MIST Study

\begin{tabular}{lllllll}
\hline & Escherichia coli & Klebsiella species & Staphylococcus aureus & Staph species (non-aureus) & Group B Strep & Beta-hemolytic Streptococcus \\
\hline Cefixime & $82 / 119^{a}(68.9 \%)$ & $34 / 36(94.4 \%)$ & $0 / 7$ & $4 / 28(14.3 \%)$ & $4 / 7(57.1 \%)$ & $11 / 11(100.0 \%)$ \\
Nitrofurantoin & $117 / 118(99.2 \%)$ & $26 / 35(74.3 \%)$ & $7 / 7(100.0 \%)$ & $28 / 28(100.0 \%)$ & $7 / 7(100.0 \%)$ & $11 / 11(100.0 \%)$ \\
Ampicillin & $40 / 119(33.6 \%)$ & $3 / 36(8.3 \%)$ & $3 / 7(42.9 \%)$ & $16 / 28(57.1 \%)$ & $7 / 7(100.0 \%)$ & $10 / 11(90.9 \%)$ \\
Azithromycin & $34 / 120(28.3 \%)$ & $3 / 36(8.3 \%)$ & $3 / 7(42.9 \%)$ & $22 / 28(78.6 \%)$ & $2 / 7(28.6 \%)$ & $6 / 11(54.5 \%)$ \\
Cotrimoxazole & $74 / 118(62.7 \%)$ & $35 / 36(97.2 \%)$ & $6 / 7(85.7 \%)$ & $23.28(82.1 \%)$ & $7 / 7(100.0 \%)$ & $11 / 11(100.0 \%)$ \\
Gentamicin & $97 / 117(82.9 \%)$ & $33 / 36(91.7 \%)$ & $6 / 7(85.7 \%)$ & $24 / 28(85.7 \%)$ & $3 / 7(42.9 \%)$ & $2 / 7(18.2 \%)$ \\
Nalidixic acid & $45 / 121(37.2 \%)$ & $33 / 36(91.7 \%)$ & $0 / 7(0.0 \%)$ & $5 / 28(17.9 \%)$ & $0 / 7(0.0 \%)$ & $0 / 11(0.0 \%)$ \\
Cetriaxone & $83 / 117(70.9 \%)$ & $31 / 35(88.6 \%)$ & $5 / 7(71.4 \%)$ & $24 / 25(96.0 \%)$ & $7 / 7(100.0 \%)$ & $11 / 11(100.0 \%)$ \\
Cephalexin & $74 / 119(62.2 \%)$ & $29 / 36(80.6 \%)$ & $6 / 7(85.7 \%)$ & $26 / 28(92.9 \%)$ & $5 / 7(71.4 \%)$ & $11 / 711(100.0 \%)$ \\
\hline
\end{tabular}

${ }^{a} \mathrm{n} / \mathrm{N}$ in each cell report the (number of bacterial isolates susceptible to the specified antibiotic)/(number of urine samples with bacterial species isolated)

9.6\%, similar to our study [27]. Two studies in urban settings in northern India reported higher prevalence of ASB and UTI, ranging from $19.9 \%$ ASB prevalence in primary care clinics [28] to $25.5 \%$ prevalence of symptomatic UTI in a tertiary care ANC clinic in Lucknow [29].

In our pregnancy cohort, the majority of women with bacteriuria in were asymptomatic. This has relevance with respect to screening procedures in LMIC. A symptomatic approach to UTI will miss the majority of cases and the opportunity for interventiontreatment to prevent maternal morbidity and adverse pregnancy outcomes. While urine culture is standard of care in high income countries (HIC), it is typically costly and requires laboratory resources, infrastructure, and personnel and is not feasible in many LMIC settings. The diagnostic accuracy of urine dipstick and gram stain for diagnosis of ASB is poor, with particularly low sensitivity [30, 31]. Lower cost, feasible, and accurate point of care methods/diagnostics for screening for ASB are urgently needed to improve detection and management of UTI in LMIC.

Primiparity, less paternal education, and maternal undernutrition were significant risk factors for UTI in this population. Poor hygiene practices may be more common in first time mothers of young age and those with low SES, and predispose them to urinary tract infection [32]. Low paternal education is a marker for low SES, a frequently reported risk factor for UTI [32]. Maternal undernutrition, defined as maternal MUAC $<23 \mathrm{~cm}$, was also observed to be a risk factor for UTI in this population. Malnutrition is an important and under-recognized cause of immunodeficiency globally [33]. Protein energy malnutrition may impair immune function (i.e. antigen-presenting cell and cell mediated T-cell function), and increase risk of maternal infections, including UTI [34-36]. Undernutrition has been identified as a risk for UTI in children [37] and the elderly [38]. However, to our knowledge, this is the first report of this association between maternal undernutrition and UTI in a pregnancy population in a LMIC.

Gram-negative organisms, E. coli and Klebsiella species, were common etiologies of UTI in Sylhet, accounting for half (38 and 12\%, respectively) of cases of significant bacteriuria. Other studies of UTI etiology in Bangladesh have similarly reported a predominance of gram negatives, particularly $E$. coli, which comprised $59-75 \%$ of isolates, and Klebsiella species, which ranged from 6 to $11 \%$ of isolates $[39,40]$. In a 5 -year, large, prospective study of pregnant women in a tertiary care hospital in India, E. coli and Klebsiella pneumoniae were the most common uro-pathogens (42 and $22 \%$ of isolates, respectively) [41].

In this population, there was also a high rate of isolation of gram-positive organisms. Specifically, staphylococcal species (non-aureus) were the second most common uro-pathogen overall, contributing to $23 \%$ of positive cultures. The majority of these isolates were presumably Staphylococcus saprophyticus, a leading cause of cystitis in young women [42]. However, our field laboratory did not have the capacity to further speciate with novobiocin resistance testing. Other studies in Bangladesh have reported that S. saprophyticus [43] comprised $11-19 \%$ of uro-pathogens [39, 44]. In India, S. saprophyticus comprised $10.6 \%$ of positive cultures [45]. While $S$. aureus is often considered skin flora, it accounted for $12 \%$ of cases of UTI in Sylhet. While precautions were taken to avoid skin contamination, it is difficult to ascertain whether the bacteriuria was due to skin contamination or whether it was a true uro-pathogen [1]. Among cases of S. aureus bacteriuria, approximately $82 \%$ were asymptomatic. S. aureus was described as an emerging etiology of UTI in LMIC in a recent global burden review [1]. In Nigeria, S. aureus comprised approximately 24 to $28 \%$ of isolates in women with bacteriuria or clinical UTI $[46,47]$. A study of pregnancy-associated ASB in Sudan reported that S. aureus comprised 39\% of cases 
[48]. A lower contribution of $S$. aureus infection was reported in India (5.9\%) [41].

Antibiotic resistance is a growing concern, particularly in LMIC, and our study demonstrates high and concerning rates of antibiotic resistance to common antimicrobial agents for treatment of UTI in pregnancy. The gram-negative uro-pathogens were highly resistant to ampicillin and azithromycin. More than $30 \%$ of $E$. coli isolates were not susceptible to common $2^{\text {nd }}$ and $3^{\text {rd }}$ generation cephalosporins. Among the most common uro-pathogens, E. coli and staphylococcal species, there was only low-to- moderate susceptibility to cefixime, a traditionally potent oral $3^{\text {rd }}$ generation cephalosporin. Similar high and concerning rates of antibiotic resistance were reported in the WHO Global Surveillance of Antimicrobials. In national level data from South-East Asia, 16-68\% of E. coli isolates, and $34-81 \%$ of Klebsiella isolates were resistant to $3^{\text {rd }}$ generation cephalosporins $[49,50]$. This data emphasizes the urgency for antibiotic stewardship in LMIC, and the need to also develop new effective antimicrobials with safety in pregnancy.

There were several limitations to this study. We did not have the ability to speciate coagulase-negative staphylococcal species in our field laboratory. We presume the majority of these species were Staphylococcus saprophyticus, however, it is possible that some of these may have been Staphylococcus epidermidis, which might be considered a skin contaminant. Another challenge is the differentiation of skin contamination vs. true pathogens. The rates of $S$. aureus growth were high, and it is difficult, if not impossible, to determine what proportion of those should be considered as UTI pathogens, particularly in asymptomatic women. While we used clean catch midstream urine specimens, the samples were collected in homes, and it is possible that some were skin contaminants. We also did not systematically collect cost data, which would have been useful to determine the cost-effectiveness of our program. There is a paucity of evidence on the cost-effectiveness of screeningtreatment programs for UTI in pregnancy, which is of particular relevance in LMICs. Finally, we did not have extensive data on several known behavioral risk factors for UTI, including sexual history or toileting practices.

\section{Conclusions}

The screening and treatment of urinary tract infections in pregnancy is standard of care in high-income countries and is now recommended by the WHO for LMIC. In rural Sylhet, Bangladesh, an estimated one in 11 pregnant women in the general population had a UTI that required antibiotic treatment. The majority of women with bacteriuria had no symptoms. Low paternal education, primparity, and maternal undernutrition were important risk factors for UTI. Rates of antibiotic resistance were concerningly high, particularly in E. coli strains. Further research is needed to identify low-cost, feasible, and accurate methods for UTI screening and to address high rates of antibiotic resistance in LMIC.

\section{Supplementary information}

Supplementary information accompanies this paper at https://doi.org/10. 1186/s12884-019-2665-0.

Additional file 1 : Table S1. Classification of Common Urinary Tract Pathogens and Non-Pathogens. Figure S1. MIST treatment algorithm for positive urine cultures. Figure S2. Etiology of bacteria among women with intermediate growth cultures who were asymptomatic.

\section{Abbreviations}

ANC: Antenatal care; ASB: Asymptomatic bacteriuria; AVF: Atypical vaginal flora; CHW: Community health worker; LMICs: Low- and middle-income countries; LMP: Last menstrual period; MIST: Maternal infection screening and treatment (study); MUAC: Mid-upper arm circumference; UTI: Urinary tract infection; WHO: World Health Organization

\section{Acknowledgments}

We would like to acknowledge the dedicated Projahnmo MIST team involved the design, conduct and implementation of this trial-management team (Rashed Shah), medical officers (Monir Zaman, Salaheen Towhid), project officers (Ashraf Eusufzi, Sadia Naznin), field supervisory staff (Ataur Rahim), laboratory team (Maksuda Islam, Roman Mortuza, Robel Partaway, Tarik Hassan, Mashuk Siddiquee, Zabed Ahmed), community health workers and village health workers. We would also like to thank Ingrid Olson for her assistance formatting the manuscript for submission. Finally, we would like to thank the mothers and infants who participated in this trial.

\section{Authors' contributions}

$A H B, A C L, L C M, P C, A L, M Q$, SS conceived and designed the study. AHB, ACL LCM, IF, MR, DM, JU, PA, SA, AM, SD, NB, MQ, SS implemented the project implementation and conducted study procedures. IR and SS performed and/ or supervised the microbiological testing, including Urine Culture and antimicrobial resistance testing; SS supervised all laboratory procedures. LCM, $A K, R K$, and $A C L$ conducted the data analysis. $L C M, A H B, A C L$ had full access to all the data in the study and take responsibility for the integrity of the data and accuracy of the data analysis. $A C L$ drafted the first version of the manuscript with LVF. All authors have read, input, and approved the final manuscript.

\section{Funding}

This work was funded by a grant from the NICHD (R01 HD066156-02). The funding body played no role in the design of the study; the collection, analysis, or interpretation of data; nor in the writing the manuscript.

\section{Availability of data and materials}

The datasets used and/or analyzed during the current study are available from the corresponding author on reasonable request.

\section{Ethics approval and consent to participate}

The study protocol was approved by the institutional review boards of Johns Hopkins Bloomberg School of Public Health Institutional Review Board (Baltimore, Maryland), International Centre for Diarrhoeal Disease Research, Bangladesh Ethical Review Committee (iccdr,b) (Dhaka, Bangladesh), and Partners Human Research Committee (Boston, MA).

Participants were enrolled after providing verbal informed consent for the main RCT. Verbal consent was obtained because the majority of the prospective study population was illiterate at the initiation of the study (2012). Documentation of verbal informed consent was formally approved by all participating institutional review boards. 
The study was explained to the study participants, questions answered, and the name of the study participant, date of consent, and name/signature of the study staff obtaining verbal consent were collected on a paper consent document. A paper copy of the consent form was provided to the study participant.

\section{Consent for publication}

Not applicable.

\section{Competing interests}

The authors declare that they have no competing interests.

\section{Author details}

'Department of Pediatric Newborn Medicine, Brigham and Women's Hospital, 75 Francis Street, Boston, MA 02115, USA. ²Department of International Health, Johns Hopkins Bloomberg School of Public Health, 615 N Wolfe St, Baltimore, MD 21205, USA. ${ }^{3}$ Department of Microbiology and Immunology, University of Mississippi Medical Center (UMMC), 2500 N State St, Jackson, MS 39216, USA. ${ }^{4}$ Maternal and Child Health Division, International Centre for Diarrhoeal Disease Research, Bangladesh (icddr,b), 68, Shaheed Tajuddin Ahmed Sarani, Mohakhali, Dhaka 1212, Bangladesh. ${ }^{5}$ North South University, Plot \#15, Block \#B, Bashundhara R/A, Dhaka 1229, Bangladesh. ${ }^{6}$ Bill and Melinda Gates Foundation, 440 5th Avenue North, Seattle, WA 98109, USA. ${ }^{7}$ Save the Children Bangladesh, House No. CWN (A) 35, Road No. 43 Gulshan 2, Dhaka 1212, Bangladesh. ${ }^{8}$ Institute of Epidemiology Disease Control and Research, Mohakhali, Dhaka 1212, Bangladesh. ${ }^{9}$ Projahnmo Research Foundation, House: 37, Road:27, Block: A, Banani, Dhaka 1213, Bangladesh. ${ }^{10}$ School of Community Health and Policy, Morgan State University, Baltimore, MD 21251, USA. ${ }^{11}$ Department of Microbiology, Dhaka Shishu Hospital, Sher-E-Banglanagar, Child Health Research Foundation, Dhaka 1207, Bangladesh.

Received: 8 October 2019 Accepted: 6 December 2019

\section{Published online: 31 December 2019}

\section{References}

1. Gilbert NM, O'Brien VP, Hultgren S, Macones $G$, Lewis WG, Lewis AL. Urinary tract infection as a preventable cause of pregnancy complications: opportunities, challenges, and a global call to action. Glob Adv Health Med. 2013;2(5):59-69.

2. Nicolle LE, Bradley S, Colgan R, Rice JC, Schaeffer A, Hooton TM, et al. Infectious diseases society of America guidelines for the diagnosis and treatment of asymptomatic bacteriuria in adults. Clin Infect Dis. 2005;40(5): 643-54

3. Nicolle LE. Screening for asymptomatic bacteriuria in pregnancy Canadian guide to clinical preventative care. Health Canada: Ottowa; 1994.

4. National Collaborating Center for Women's and Children's Health Antenatal care: routine care for the healthy pregnant woman. London: RCOG Press; 2008.

5. World Health Organization (WHO). WHO recommendations on antental care for a positive pregnancy experience. Geneva: 2016.

6. Gebre-Selassie S. Asymptomatic bacteriuria in pregnancy: epidemiological, clinical and microbiological approach. Ethiop Med J. 1998;36(3):185-92.

7. Akerele J, Abhulimen P, Okonofua F. Prevalence of asymptomatic bacteriuria among pregnant women in Benin City, Nigeria. J Obstet Gynaecol. 2001; 21(2):141-4

8. Whalley P. Bacteriuria of pregnancy. Am J Obstet Gynecol. 1967;97(5):723-38.

9. Romero R, Gotsch F, Pineles B, Kusanovic JP. Inflammation in pregnancy: its roles in reproductive physiology, obstetrical complications, and fetal injury. Nutr Rev. 2007;65(12 Pt 2):S194-202.

10. Hill JBSJ, McIntire DD, Wendel GD Jr. Acute pyelonephritis in pregnancy. Obstet Gynecol. 2005;105:18-23.

11. Kass EH. Bacteriuria and pyelonephritis of pregnancy. Arch Intern Med. 1960; 105:194-8.

12. Kass EH. Pyelonephritis and bacteriuria. A major problem in preventive medicine. Ann Intern Med. 1962;56:46-53.

13. Romero R, Oyarzun E, Mazor M, Sirtori M, Hobbins JC, Bracken M. Metaanalysis of the relationship between asymptomatic bacteriuria and preterm delivery/low birth weight. Obstet Gynecol. 1989;73(4):576-82.

14. Barros FCBZ, Batra M, Hansen TN, Victora CG, Rubens CE. GAPPS Review Group. Global report on preterm birth and stillbirth (3 of 7): evidence for effectiveness of interventions. BMC Pregnancy Childbirth. 2010; 10(Suppl 1):S3.

15. McClure EM, Goldenberg RL. Infection and stillbirth. Semin Fetal Neonatal Med. 2009:14(4):182-89.

16. Chan GJ, Lee AC, Baqui AH, Tan J, Black RE. Risk of early-onset neonatal infection with maternal infection or colonization: a global systematic review and meta-analysis. PLoS Med. 2013;10(8):e1001502.

17. Lee AC, Quaiyum MA, Mullany LC, Mitra DK, Labrique A, Ahmed P, et al. Screening and treatment of maternal genitourinary tract infections in early pregnancy to prevent preterm birth in rural Sylhet, Bangladesh: a cluster randomized trial. BMC Pregnancy Childbirth. 2015;15:326.

18. Lee AC, Mullany LC, Quaiyum M, Mitra DK, Labrique A, Christian P, et al. Effect of population-based antenatal screening and treatment of genitourinary tract infections on birth outcomes in Sylhet, Bangladesh (MIST): a cluster-randomised clinical trial. Lancet Glob Health. 2019;7(1): e148-e59.

19. Bangladesh Demographic and Health Survey 2014. Dhaka, Bangladesh and Rockville, Maryland: National Institute of Population Research and Training (NIPORT), Mitra and Associates, and ICF International; 2016.

20. Baqui AH, Lee ACC, Koffi AK, Khanam R, Mitra DK, Dasgupta SK, et al. Prevalence of and risk factors for abnormal vaginal flora and its association with adverse pregnancy outcomes in a rural district in north-East Bangladesh. Acta Obstet Gynecol Scand. 2019;98(3):309-19.

21. Shaifali I, Gupta U, Mahmood SE, Ahmed J. Antibiotic susceptibility patterns of urinary pathogens in female outpatients. N Am J Med Sci. 2012;4(4):163-9.

22. ACOG Practice Bulletin No. 91: treatment of urinary tract infections in nonpregnant women. Obstet Gynecol 2008;111(3):785-794.

23. Filmer D, Pritchett LH. Estimating wealth effects without expenditure data-or tears: an application to educational enrollments in states of India. Demography. 2001;38(1):115-32.

24. Razzaque SM, Rahman KM. Bacteriuria and urinary tract infection in pregnancy. Bangladesh Med Res Counc Bull. 1977;3(2):145-8.

25. Ullah A, Barman A, Ahmed I, Salam A. Asymptomatic bacteriuria in pregnant mothers: a valid and cost-effective screening test in Bangladesh. J Obstet Gynaecol. 2012;32(1):37-41.

26. Ullah MA, Barman A, Siddique MA, Haque AK. Prevalence of asymptomatic bacteriuria and its consequences in pregnancy in a rural community of Bangladesh. Bangladesh Med Res Counc Bull. 2007:33(2):60-4.

27. Thakre SS, Dhakne SS, Thakre SB, Thakre AD, Ughade SM, Kale P. Can the Griess nitrite test and a urinary pus cell count of $>/=5$ cells per micro litre of urine in pregnant women be used for the screening or the early detection of urinary tract infections in rural India? J Clin Diagn Res. 2012; 6(9):1518-22

28. Bandyopadhyay S, Thakur JS, Ray P, Kumar R. High prevalence of bacteriuria in pregnancy and its screening methods in North India. J Indian Med Assoc. 2005;103(5):259-62 66

29. Lata I, Pradeep Y, Sujata JA. Estimation of the incidence of bacterial Vaginosis and other vaginal infections and its consequences on maternal/ fetal outcome in pregnant women attending an antenatal Clinic in a Tertiary Care Hospital in North India. Indian J Community Med. 2010;35(2): 285-9.

30. Rogozinska E, Formina S, Zamora J, Mignini L, Khan KS. Accuracy of onsite tests to detect asymptomatic Bacteriuria in pregnancy: a systematic review and meta-analysis. Obstet Gynecol. 2016;128(3):495-503.

31. Ajayi AB, Nwabuisi C, Aboyeji PO, Fowotade A, Fakeye OO. Reliability of urine multistix and gram stain in the detection of asymptomatic bacteriuria in pregnancy. West Afr J Med. 2010;29(5):339-43.

32. Schnarr J, Smaill F. Asymptomatic bacteriuria and symptomatic urinary tract infections in pregnancy. Eur J Clin Investig. 2008;38(Suppl 2):50-7.

33. Katona $\mathrm{P}$, Katona-Apte J. The interaction between nutrition and infection. Clin Infect Dis. 2008:46(10):1582-8.

34. Raiten DJ, Sakr Ashour FA, Ross AC, Meydani SN, Dawson HD, Stephensen $\mathrm{CB}$, et al. Inflammation and nutritional science for programs/policies and interpretation of research evidence (INSPIRE). J Nutr. 2015;145(5):1039S$108 \mathrm{~S}$.

35. Ahmad SM, Haskell MJ, Raqib R, Stephensen CB. Vitamin a status is associated with T-cell responses in Bangladeshi men. Br J Nutr. 2009;102(6): 797-802.

36. Hughes SM, Amadi B, Mwiya M, Nkamba H, Tomkins A, Goldblatt D. Dendritic cell anergy results from endotoxemia in severe malnutrition. J Immunol. 2009;183(4):2818-26. 
37. Bagga A, Tripathi P, Jatana V, Hari P, Kapil A, Srivastava RN, et al. Bacteriuria and urinary tract infections in malnourished children. Pediatric Nephrol. 2003;18(4):366-70.

38. Carlsson M, Haglin L, Rosendahl E, Gustafson Y. Poor nutritional status is associated with urinary tract infection among older people living in residential care facilities. J Nutr Health Aging. 2013;17(2):186-91.

39. Haque R, Akter ML, Salam MA. Prevalence and susceptibility of uropathogens: a recent report from a teaching hospital in Bangladesh. BMC Res Notes. 2015;8:416.

40. Majumder Ml, Ahmed T, Hossain D, Begum SA. Bacteriology and antibiotic sensitivity patterns of urinary tract infections in a tertiary hospital in Bangladesh. Mymensingh Med J. 2014;23(1):99-104.

41. Rizvi M, Khan F, Shukla I, Malik A. Shaheen. Rising prevalence of antimicrobial resistance in urinary tract infections during pregnancy: necessity for exploring newer treatment options. J Lab Physicians. 2011;3(2): 98-103

42. Raz R, Colodner R, Kunin CM. Who are you--Staphylococcus saprophyticus? Clin Infect Dis. 2005:40(6):896-8.

43. Becker K, Heilmann C, Peters G. Coagulase-negative staphylococci. Clin Microbiol Rev. 2014;27(4):870-926.

44. Parvin US, Hossain MA, Musa AK, Mahamud C, Islam MT, Haque N, et al. Pattern of aerobic bacteria with antimicrobial susceptibility causing community acquired urinary tract infection. Mymensingh Med J. 2009;18(2): 148-53.

45. Jayalakshmi J, Jayaram VS. Evaluation of various screening tests to detect asymptomatic bacteriuria in pregnant women. Indian J Pathol Microbiol. 2008;51(3):379-81.

46. Imade PE, Izekor PE, Eghafona NO, Enabulele Ol, Ophori E. Asymptomatic bacteriuria among pregnant women. N Am J Med Sci. 2010;2(6):263-6.

47. Oli AN, Akabueze VB, Ezeudu CE, Eleje GU, Ejiofor OS, Ezebialu IU, et al. Bacteriology and Antibiogram of urinary tract infection among female patients in a tertiary health Facility in South Eastern Nigeria. Open Microbiol J. 2017:11:292-300

48. Hamdan $\mathrm{HZ}$, Ziad AH, Ali SK, Adam I. Epidemiology of urinary tract infections and antibiotics sensitivity among pregnant women at Khartoum north hospital. Ann Clin Microbiol Antimicrob. 2011;10:2.

49. Antimicrobial Resistance Global Report on Surveillance. Geneva, Switzerland World Health Organization (WHO); 2014

50. The world is running out of antibiotics, WHO report confirms [press release]. 2017. https://www.who.int/news-room/detail/20-09-2017-the-world-isrunning-out-of-antibiotics-who-report-confirms.

\section{Publisher's Note}

Springer Nature remains neutral with regard to jurisdictional claims in published maps and institutional affiliations.

Ready to submit your research? Choose BMC and benefit from:

- fast, convenient online submission

- thorough peer review by experienced researchers in your field

- rapid publication on acceptance

- support for research data, including large and complex data types

- gold Open Access which fosters wider collaboration and increased citations

- maximum visibility for your research: over $100 \mathrm{M}$ website views per year

At $\mathrm{BMC}$, research is always in progress.

Learn more biomedcentral.com/submissions 